\title{
Effects of covariates and interactions on a genome-wide association analysis of rheumatoid arthritis
}

\author{
Rector Arya*1,2, Elizabeth Hare ${ }^{3}$, Inmaculada del Rincon ${ }^{4}$, \\ Christopher P Jenkinson ${ }^{5}$, Ravindranath Duggirala ${ }^{6}$, Laura Almasy ${ }^{6}$ \\ and Agustin Escalante ${ }^{4}$
}

Addresses: ${ }^{1}$ Division of Clinical Epidemiology, Department of Medicine, University of Texas Health Science Center, 7703 Floyd Curl Drive, San Antonio, Texas 78229, USA, ${ }^{2}$ Medical Center Research Division, Edinburg-Regional Academic Health Center, University of Texas Health Science Division, 1214 West Schunior, Edinburg, Texas 78541, USA, ${ }^{3}$ Department of Psychiatry, University of Texas Health Science Center, 7703 Floyd Curl Drive, San Antonio, Texas 78229, USA, ${ }^{4}$ Division of Clinical Immunology, Department of Medicine, University of Texas Health Science Center, 7703 Floyd Curl Drive, San Antonio, Texas 78229, USA, ${ }^{5}$ Division of Diabetes, Department of Medicine, University of Texas Health Science Center, 7703 Floyd Curl Drive, San Antonio, Texas 78229, USA and ${ }^{6}$ Department of Genetics, Southwest Foundation for Biomedical Research, 7620 NW Loop 410, San Antonio, Texas 78245, USA

E-mail: Rector Arya* - arya@uthscsa.edu; Elizabeth Hare - hare@uthscsa.edu; Inmaculada del Rincon - delrincon@uthscsa.edu; Christopher P Jenkinson - Jenkinsonc@uthscsa.edu ; Ravindranath Duggirala - ravid@sfbrgenetics.org; Laura Almasy - almasy@uthscsa.edu; Agustin Escalante - escalante@uthscsa.edu

*Corresponding author

from Genetic Analysis Workshop 16

St Louis, MO, USA 17-20 September 2009

Published: 15 December 2009

BMC Proceedings 2009, 3(Suppl 7):S84 doi: 10.1186/1753-656I-3-S7-S84

This article is available from: http://www.biomedcentral.com/I753-656I/3/S7/S84

(c) 2009 Arya et al; licensee BioMed Central Ltd.

This is an open access article distributed under the terms of the Creative Commons Attribution License (http://creativecommons.org/licenses/by/2.0), which permits unrestricted use, distribution, and reproduction in any medium, provided the original work is properly cited.

\begin{abstract}
While genetic and environmental factors and their interactions influence susceptibility to rheumatoid arthritis (RA), causative genetic variants have not been identified. The purpose of the present study was to assess the effects of covariates and genotype $\times$ sex interactions on the genome-wide association analysis (GWAA) of RA using Genetic Analysis Workshop 16 Problem I data and a logistic regression approach as implemented in PLINK. After accounting for the effects of population stratification, effects of covariates and genotype $x$ sex interactions on the GWAA of RA were assessed by conducting association and interaction analyses. We found significant allelic associations, covariate, and genotype $x$ sex interaction effects on RA. Several top single-nucleotide polymorphisms (SNPs) ( 22 SNPs) showed significant associations with strong $p$-values $\left(p<1 \times 10^{-4}-p<1 \times 10^{-24}\right)$. Only three SNPs on chromosomes 4,13 , and 20 were significant after Bonferroni correction, and none of these three SNPs showed significant genotype $\times$ sex interactions. Of the 30 top SNPs with significant $\left(p<1 \times 10^{-4}-p<1 \times\right.$ $10^{-6}$ ) interactions, $\sim 23$ SNPs showed additive interactions and $\sim 5$ SNPs showed only dominance interactions. Those SNPs showing significant associations in the regular logistic regression failed to show significant interactions. In contrast, the SNPs that showed significant interactions failed to show significant associations in models that did not incorporate interactions. It is important to consider interactions of genotype $\times$ sex in addition to associations in a GWAA of RA. Furthermore, the association between SNPs and RA susceptibility varies significantly between men and women.
\end{abstract}




\section{Background}

Rheumatoid arthritis (RA) is a chronic inflammatory disease of the joints, of unknown cause. It affects around $2 \%$ of people 60 years and older, but occurs in people of all ages. Women are more susceptible to RA than are men, and the disease is more frequent in some Native North American groups [1]. Inflammation in RA centers on the joints, causing joint swelling, pain, and degradation of joint cartilage and bone.

Genetic factors influence RA susceptibility [2,3]. Although family and twin studies suggest a genetic contribution to RA susceptibility of about 50-60\%, causative genetic variants have not been identified $[4,5]$. Furthermore, genome-wide linkage studies of both discrete and continuous traits (RF-IgM and antiCCP phenotypes) have shown strong evidence for linkages with several loci including chromosomes 6 and 18. Moreover, some genetic systems are strongly linked to disease susceptibility and to the disease phenotype. Recent association studies have implicated the HLA region on $6 \mathrm{p}$, which accounts for about $30 \%$ of heritable risk [6]. The most studied gene associated with joint damage in RA is HLA-DRB1 [7]. However, genes from non-HLA regions are largely unknown.

Given that genome-wide association analysis (GWAA) is explicitly designed to detect genetic variants under the common-disease common-variant (CDCV) model for complex traits such as RA, it was expected that GWAA would capture most common genetic variation in RA. Because RA results from the interplay between an individual's genetic background and unknown environmental factors, it is important to assess the effects of environmental factors and their interactions on RA. Using Genetic Analysis Workshop (GAW) 16 data, we assessed the effects of covariates and interactions on the GWAA of RA. The only such factor available in the dataset we studied was sex. Although sex is not itself an environmental factor, it can serve as a model for how environmental variables and gene $\times$ environment interactions could be treated in the GWAA of RA. In addition to being a strong RA susceptibility factor, there is published evidence of heterogeneity by sex in the association of certain genetic systems.

\section{Methods \\ Subjects}

For this GAW16 analysis, the GAW16 RA data (Problem 1) from the North American Rheumatoid Arthritis Consortium (NARAC) cases $(n=868)$ and matched controls $(n=$ 1194) have been used. For the NARAC study, patients were drawn from rheumatology clinics across North America who were anti-CCP-positive and met the criteria for RA adopted by the American College of Rheumatology in 1987 . The NARAC samples $(n=2062)$ were from multiplex families in which at least one sibling had obvious erosions as seen on radiography of the hand, and at least one sibling had an onset of RA between the ages of 18 and 60 years.

\section{Genotyping}

As described in Padyukov et al., [8] SNP genotyping was performed at the Feinsterin Institute for Medical Research Samples according to the Illumina Infinium 2 assay manual (Illumina, San Diego). All cases and most of the control samples were genotyped with the HumanHap550k beadchip.

\section{Association analysis}

We performed a population-based genome-wide association analysis using PLINK, a tool set for whole genome association [9]. We analyzed GAW16 Problem 1 data using a variety of analyses: stratification, association, and interaction analyses using PLINK software [9]. We used the structured association approach, a simple but powerful approach, to detect population stratification, as implemented in the PLINK software [9-11]. PLINK's clustering approach is based on the genome-wide average proportion of alleles shared identical-by-state (IBS) between two individuals, i.e., pairing up individuals based on genetic identity. IBS clustering is used to test whether two individuals belong to the same population. Following the stratification analysis, we performed a standard case-control association test using a CochranMantel-Haenszel statistic (1 df) that tests for singlenucleotide polymorphism (SNP)-disease association conditional on the clustering i.e., accounts for stratification effects. We used the most stringent Bonferroni correction (BONF) as well as the less stringent Benjamini and Hochberg false discovery rate (BH-FDR) for multiple testing corrections.

\section{Interaction analysis}

The covariates for a discrete trait (RA affection status) included sex and genotypic models: additive (ADD), dominant deviation (DD), and general (GM). An additive model represents the additive effects of SNPs i.e., the effect of each additional minor allele as represented by the direction of the regression coefficient. For example, a positive regression coefficient indicates that the minor allele increases risk. A DD model represents a separate test of the dominance component, and a general model represents the joint test of both $\mathrm{ADD}$ and DD components. However, in contrast to a dominance model, DD refers to a variable coded in such a way $(0,1,0$ for three genotypes $\mathrm{AA}, \mathrm{Aa}$, aa) that it represents the dominance deviation from additivity 
without specifying whether a particular allele is dominant or recessive. Effects of genotype $\times$ sex interactions: ADD $\times$ Sex and DD $\times$ Sex were assessed using a logistic regression approach as implemented in PLINK.

\section{Results}

Using RA case status as affected and unaffected, we performed a general association and genotype $\times$ sex interaction analyses to identify those loci associated with RA. Given that the NARAC sample was stratified due to the presence of subpopulations, we performed the association analyses accounting for the population stratification. We found significant allelic associations, covariate (sex), and genotype $\times$ sex interaction effects on RA. The results of the association analyses are presented in Figure 1 and Table 1. In Figure 1, plot A shows associations across the entire genome and plot $\mathrm{B}$ shows associations in non-HLA regions. In Table 1, top SNPs ( 22 SNPs with the best SNP on each chromosome) with strongest $p$-values (ranging from $p<1 \times 10^{-4}$ to $p<1 \times$ $10^{-24}$ ) were presented along with corrected $p$-values for multiple testing, and genotype $\times$ sex interaction $p$-values. As shown in Table 1, the most strongly associated SNP $\left(p<1 \times 10^{-8}\right)$ in a non-HLA region was on chromosome $4, \operatorname{rs} 512244\left(p=8.362 \times 10^{-8}\right)$. Only three SNPs on chromosomes 4, 13, and 20 survived the overly conservative Bonferroni correction, and none of these three SNPs showed significant genotype $\times$ sex interactions. Interestingly, the Benjamini and Hochberg's false discovery rate (BHFDR), an alternative multiple testing correction, also yielded very similar $p$-values as shown in Tables 1 and 2.

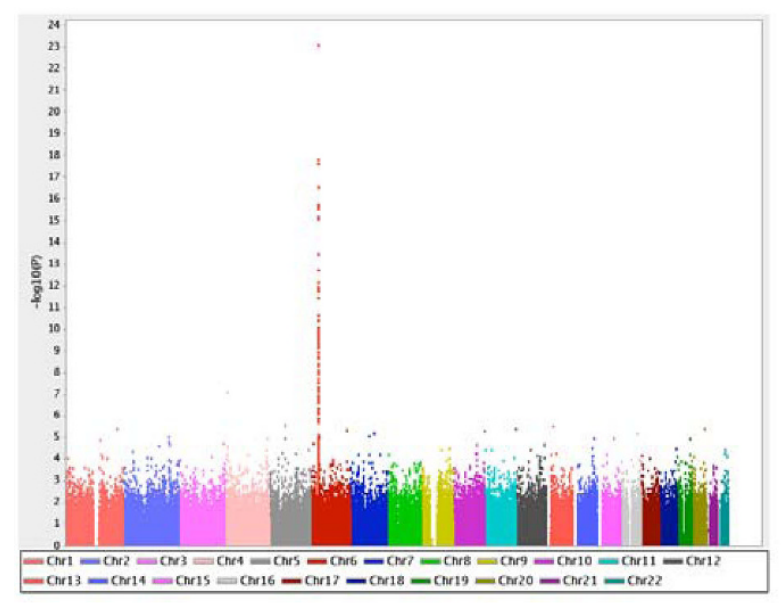

$\operatorname{Plot} \mathbf{A}$
In the genotype $\times$ sex interaction analysis, we identified a new set of SNPs to be highly significant in the presence of genotype $\times$ sex interaction, which showed no significance in the allelic association model. In Table 2, top SNPs showing significant interaction effects were presented along with corresponding association $p$-values for comparison. Out of 30 top SNPs with significant interactions $(p<1 \times$ $10^{-4}$ to $p<1 \times 10^{-6}$ ) shown in Table 2, 23 SNPs showed ADD $\times$ Sex and $\sim 5$ SNPs showed only DD $\times$ Sex interactions. Interestingly, the evidence of significance was reduced for most of the top SNPs showing association with RA in Table 1 in the presence of interactions as shown in Table 2. On the other hand, most of the SNPs showing highly significant effects of genotype $\times$ sex interactions (Table 2) showed no significant associations with RA (Table 1). Among covariates, two SNPs (on chromosomes 1 and 10) showed highly significant sex effects $(p<1 \times$ $\left.10^{-4}\right)$, five SNPs showed additive effects, and two SNPs showed DD effects (Table 2). The observed differences between men and women in RA susceptibility may be attributable to the differences according to sex in their susceptibility to the disease and in the expression of clinical phenotype of RA.

\section{Discussion}

In this study, we performed a population-based GWAA and genotype $\times$ sex interaction analyses using the GAW16 RA data (Problem 1) from NARAC. We performed association analyses without correcting for population stratification and found interesting associations (results not shown). Because the NARAC populations consisted of substructures, we repeated association

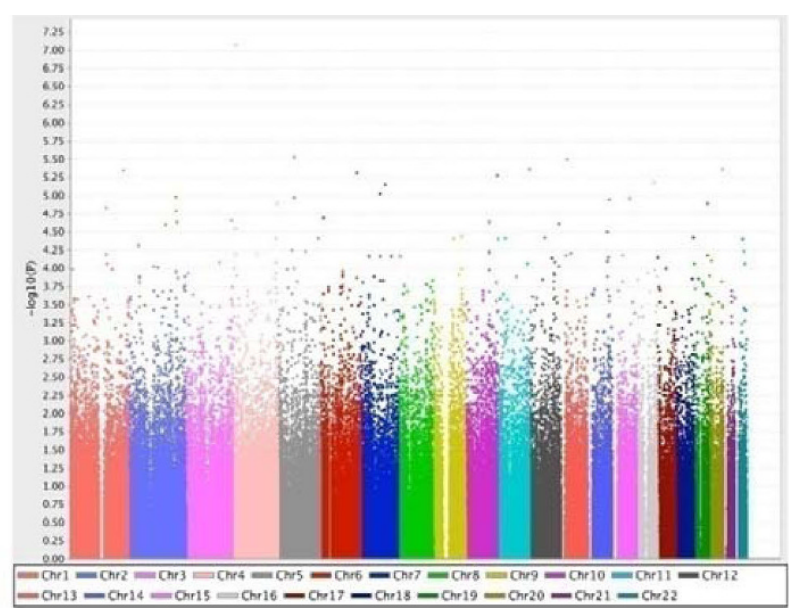

Plot B

Figure I

Association plot of RA NARAC SNP data with HLA (Plot A) and without HLA (Plot B) regions. 
Table I: Genome-wide association of SNPs with RA in NARAC sample, best SNP on each chromosome

\begin{tabular}{|c|c|c|c|c|c|c|c|c|}
\hline Chr & SNP & Position & $\begin{array}{l}\text { Minor allele/ } \\
\text { major allele }\end{array}$ & $\begin{array}{c}\text { Association } \\
\text { p-value }\end{array}$ & Allelic OR (95\% CI) & $\begin{array}{l}\text { Bonferroni } \\
\text { adjusted } p \text { - } \\
\text { value }\end{array}$ & $\begin{array}{c}\text { BH-false } \\
\text { discovery } \\
\text { rate } p \text {-value }\end{array}$ & $\begin{array}{c}\text { Interaction } \\
\text { (ADD } \times \text { sex) } \\
\text { p-value }\end{array}$ \\
\hline 1 & rs865682 & $223,080,777$ & $A / G$ & $4.545 \times 10^{-6}$ & $0.39(0.26-0.60)$ & 0.16 & 0.16 & - \\
\hline 2 & rs 12477038 & $201,518,282$ & $\mathrm{G} / \mathrm{A}$ & $1.038 \times 10^{-5}$ & $0.47(0.33-0.66)$ & 0.41 & 0.25 & 0.09 \\
\hline 3 & rs6775I37 & $|93,649,85|$ & $\mathrm{A} / \mathrm{C}$ & $2.124 \times 10^{-5}$ & $0.65(0.53-0.79)$ & 0.70 & 0.70 & - \\
\hline 4 & rs512244 & $|2,775,15|$ & $\mathrm{G} / \mathrm{A}$ & $8.362 \times 10^{-8}$ & $2.2(1.7-3.0)$ & 0.002 & 0.002 & 0.14 \\
\hline 5 & rs7726943 & $67,854,337$ & $\mathrm{G} / \mathrm{A}$ & $2.991 \times 10^{-6}$ & $0.62(0.50-0.76)$ & 0.09 & 0.09 & 0.21 \\
\hline 6 & rs660895 & $32,685,358$ & $\mathrm{G} / \mathrm{A}$ & $8.346 \times 10^{-24}$ & $3.4(2.7-4.3)$ & $2.642 \times 10^{-19}$ & $2.642 \times 10^{-19}$ & $5.263 \times 10^{-45}$ \\
\hline 7 & rs17470799 & $100,768,534$ & $\mathrm{~A} / \mathrm{G}$ & $6.937 \times 10^{-6}$ & $0.4(0.27-0.60)$ & 0.18 & 0.12 & 1.0 \\
\hline 8 & rs96656I & $6,642,801$ & $A / G$ & $6.817 \times 10^{-5}$ & $0.68(0.56-0.82)$ & 1.0 & 0.54 & 0.93 \\
\hline 9 & rs306772 & $121,171,909$ & $\mathrm{~A} / \mathrm{G}$ & $3.559 \times 10^{-5}$ & $1.7(1.3-2.1)$ & 0.83 & 0.40 & 0.09 \\
\hline 10 & rs7072006 & $133,595,618$ & $\mathrm{~A} / \mathrm{G}$ & $5.309 \times 10^{-6}$ & $0.48(0.35-0.67)$ & 0.13 & 0.13 & 0.78 \\
\hline II & rs76|453 & $31,834,576$ & $\mathrm{~A} / \mathrm{G}$ & $3.867 \times 10^{-5}$ & $0.61(0.48-0.77)$ & 0.91 & 0.46 & 0.52 \\
\hline 12 & rs2283275 & $2,054,821$ & $\mathrm{G} / \mathrm{A}$ & $4.362 \times 10^{-6}$ & $0.59(0.47-0.74)$ & 0.10 & 0.10 & 0.98 \\
\hline 13 & rs 17086849 & $28,064,399$ & $\mathrm{~A} / \mathrm{G}$ & $3.158 \times 10^{-6}$ & $0.56(0.44-0.72)$ & 0.06 & 0.06 & 0.94 \\
\hline 14 & rs 12885166 & $92,195,035$ & $\mathrm{~A} / \mathrm{C}$ & $1.139 \times 10^{-5}$ & $1.6(1.3-1.9)$ & 0.18 & 0.18 & 0.45 \\
\hline 15 & rsII857639 & $71,424,825$ & $\mathrm{~A} / \mathrm{G}$ & $1.083 \times 10^{-5}$ & $0.39(0.25-0.6 \mathrm{I})$ & 0.16 & 0.16 & 1.0 \\
\hline 16 & rs107625I & $73,326,313$ & $\mathrm{~A} / \mathrm{C}$ & $6.524 \times 10^{-6}$ & $0.59(0.46-0.74)$ & 0.10 & 0.10 & 0.21 \\
\hline 17 & rs1039519 & $3,394,664$ & $\mathrm{G} / \mathrm{A}$ & $7.11 \times 10^{-5}$ & $1.52(1.2-1.9)$ & 0.90 & 0.60 & - \\
\hline 18 & rs2174899 & $72,420,808$ & $\mathrm{G} / \mathrm{A}$ & $3.671 \times 10^{-5}$ & $0.57(0.44-0.75)$ & 0.54 & 0.54 & - \\
\hline 19 & rs9630874 & $57,6 \mid 9,851$ & $\mathrm{~A} / \mathrm{C}$ & $1.27 \times 10^{-5}$ & $0.31(0.17-0.54)$ & 0.10 & 0.10 & $0.5 I$ \\
\hline 20 & rsII8253| & $57,826,397$ & $\mathrm{~A} / \mathrm{C}$ & $4.314^{-6}$ & $0.56(0.43-0.7 I)$ & 0.05 & 0.05 & 0.17 \\
\hline 21 & rs 12626622 & $31,981,460$ & $\mathrm{~A} / \mathrm{G}$ & $2.063 \times 10^{-4}$ & $1.8(1.3-2.4)$ & 1.0 & 0.52 & 0.20 \\
\hline 22 & rs3830104 & $35,033,124$ & $\mathrm{G} / \mathrm{A}$ & $3.974 \times 10^{-5}$ & $2.3(1.5-3.5)$ & 0.29 & 0.21 & 0.73 \\
\hline
\end{tabular}

analyses correcting for stratification, which made a significant difference in the association results. For example, in the first association analysis, a SNP (rs2476601) in the PTPN22 gene, an excellent candidate gene on chromosome 1 for RA, showed a highly significant $\left(1.784 \times 10^{-12}\right)$ association with RA but the signal disappeared in the subsequent analysis after correction for stratification effects $\left(p=4.748 \times 10^{-4}\right)$. Furthermore, majority of the SNPs turned out to be insignificant after correcting for multiple testing using the Bonferroni correction, an overly conservative approach, and the BH-FDR, a less stringent correction that tolerates more false positives.

Following the main-effects association analysis, we performed interaction analyses to assess the effects of covariates and genotype $\times$ sex interactions on GWAA of RA. Sex was the only "environmental" covariate available to us. Although sex does not reflect environmental exposure in the traditional sense of a factor external to the individual, sex does significantly influence a person's internal environment in terms of hormonal actions and the like. Sex may also influence a person's exposure to external substances such as hair dyes, cosmetics, and fragrances. We found significant covariate and interaction effects on RA. Interestingly, SNPs showing significant main-effects associations did not show significant interactions. In contrast, the SNPs that showed the strongest evidence for interactions did not show significant main-effect associations. This finding reveals that in a GWAA, it is important to consider genotype (additive or dominant) by sex interaction effects on RA in addition to main-effects associations. Otherwise, such variants may be missed. In other words, the list of SNPs that would be followed up for replication or confirmation changes with the genotype $x$ sex interaction effects.

On the other hand, SNPs with significant genotype $\times$ sex interaction did not necessarily have a significant (or even suggestive) main effect association. Therefore, limiting interaction tests to markers with significant main effects would likely find different results. We cannot say whether this would lose power or would protect against false positives on the basis of these results because the underlying genetic architecture of RA is largely unknown. For example, outside of the HLA region, there are $69 p$-values of $10^{-5}$ or better for the standard association analysis, so the top 100 SNPs would certainly be different if chosen using both standard association and genotype $x$ sex interaction. However, genotype $x$ sex interaction increases the multiple testing problem, and an exceedingly low $p$-value may be required to be considered significant after correction. In this study, the association between SNPs and RA susceptibility varies significantly between men and women. These results further support our earlier observation that there was significant heterogeneity between men and women, in the susceptibility and severity effects of HLA-DRB1, men being more susceptible to this gene system's influence [12]. 
Table 2: Covariate and genotype $x$ sex interaction effects on RA in NARAC sample

\begin{tabular}{|c|c|c|c|c|c|c|c|c|c|c|c|}
\hline \multirow[b]{2}{*}{ Chr } & \multirow[b]{2}{*}{ SNP } & \multirow[b]{2}{*}{ Position } & \multicolumn{9}{|c|}{$p$-Value } \\
\hline & & & Unadj & j Bonferroni & $\begin{array}{l}\text { BH- } \\
\text { FDR }\end{array}$ & Sex & ADD & DD & $\begin{array}{c}\text { General } \\
\text { model }\end{array}$ & ADD $\times$ Sex & DD $\times$ Sex \\
\hline 1 & rs9729|57 & $19,363,907$ & 0.88 & 1.0 & 0.99 & 0.6 & 0.09 & 0.91 & 0.23 & $3.029 \times 10^{-4}$ & 0.02 \\
\hline i & rsII2II044 & $44,987,845$ & 0.03 & 1.0 & 0.82 & $4.614 \times 10^{-4}$ & 0.17 & 0.02 & 0.004 & 0.86 & $7.327 \times 10^{-5}$ \\
\hline 2 & rs280734 & $35,016,040$ & 0.96 & 1.0 & 0.99 & 0.02 & 0.03 & 0.20 & 0.06 & $6.828 \times 10^{-5}$ & 0.04 \\
\hline 2 & rs49537I7 & $43,|86,55|$ & 0.96 & 1.0 & 0.99 & 0.65 & 0.47 & 0.01 & 0.02 & 0.02 & $8.957 \times 10^{-6}$ \\
\hline 3 & rs1391769 & $69,656,092$ & 0.96 & 1.0 & 0.98 & 0.01 & 0.02 & 0.31 & 0.06 & $7.111 \times 10^{-5}$ & 0.04 \\
\hline 3 & rs 17032482 & $1,045,039$ & 0.46 & 1.0 & 0.97 & 0.61 & 0.05 & $1.752 \times 10^{-4}$ & $4.623 \times 10^{-4}$ & 0.15 & $1.239 \times 10^{-4}$ \\
\hline 4 & rs68|I|287 & $9,857,092$ & 0.13 & 1.0 & 0.95 & 0.003 & 0.02 & 0.63 & 0.04 & $6.938 \times 10^{-6}$ & 0.10 \\
\hline 4 & rs $1264617 \mid$ & $24,755,192$ & 0.38 & 1.0 & 0.97 & 0.38 & 0.99 & 0.12 & 0.25 & 0.26 & $7.627 \times 10^{-5}$ \\
\hline 5 & rs7725288 & $36,364,063$ & 0.85 & 1.0 & 0.99 & 0.003 & 0.02 & 0.54 & 0.04 & $2.19 \times 10^{-6}$ & 0.688 \\
\hline 5 & rs6595726 & $126,044,143$ & 0.44 & 1.0 & 0.97 & 0.049 & 0.13 & 0.02 & 0.04 & 0.2027 & $1.234 \times 10^{-4}$ \\
\hline 6 & rs49387I & $33,673,452$ & 0.60 & 1.0 & 0.98 & 0.008 & 0.02 & 0.92 & 0.08 & $1.989 \times 10^{-5}$ & 0.64 \\
\hline 6 & rs1023107 & $14,138,449$ & 0.74 & 1.0 & 0.98 & 0.54 & 0.16 & 0.019 & 0.06 & $6.545 \times 10^{-4}$ & $3.56 \times 10^{-4}$ \\
\hline 7 & rs 12718890 & $54,528,684$ & 0.96 & 1.0 & 0.98 & 0.009 & 0.07 & 0.13 & 0.11 & $1.146 \times 10^{-4}$ & 0.12 \\
\hline 8 & rs 10090327 & $87,|| 5,02 \mid$ & 0.75 & 1.0 & 0.99 & 0.02 & 0.05 & 0.35 & 0.15 & $5.127 \times 10^{-5}$ & 0.02 \\
\hline 8 & rs4873802 & $144,691,998$ & 0.11 & 1.0 & 0.98 & 0.62 & 0.02 & $1.956 \times 10^{-6}$ & $8.096 \times 10^{-6}$ & 0.008 & 0.07 \\
\hline 9 & rs|4I3334 & $80,148,584$ & 0.43 & 1.0 & 0.96 & 0.57 & 0.004 & 0.005 & 0.007 & $1.319 \times 10^{-4}$ & 0.03 \\
\hline 9 & rs|073888| & $32,153,679$ & 0.09 & 1.0 & 0.88 & 0.67 & $9.614 \times 10^{-5}$ & 0.02 & $4.968 \times 10^{-4}$ & 0.002 & $5.619 \times 10^{-5}$ \\
\hline 10 & rs 12412942 & $2,347,702$ & 0.05 & 1.0 & 0.84 & $1.277 \times 10^{-4}$ & $3.007 \times 10^{-4}$ & 0.9816 & $8.523 \times 10^{-4}$ & $3.414 \times 10^{-4}$ & 0.42 \\
\hline II & rsI528648 & $14,096,262$ & 0.66 & 1.0 & 0.99 & 0.006 & 0.08 & 0.13 & 0.16 & $1.219 \times 10^{-4}$ & 0.17 \\
\hline 12 & rs6539583 & $75,591,349$ & 0.36 & 1.0 & 0.95 & 0.24 & 0.18 & 0.34 & 0.36 & $7.358 \times 10^{-5}$ & 0.07 \\
\hline 13 & rs $1773 \mid 26$ & $46,123,327$ & 0.26 & 1.0 & 0.96 & 0.02 & 0.10 & 0.74 & 0.21 & $1.307 \times 10^{-4}$ & 0.80 \\
\hline 14 & rs4294750 & $104,034,158$ & 0.35 & 1.0 & 0.95 & 0.30 & $6.582 \times 10^{-4}$ & 0.10 & 0.002 & $8.144 \times 10^{-5}$ & 0.06 \\
\hline 15 & rs2472297 & $72,814,933$ & 0.20 & 1.0 & 0.92 & 0.87 & $4.194 \times 10^{-6}$ & 0.04 & $1.389 \times 10^{-5}$ & $2.078 \times 10^{-4}$ & 0.006 \\
\hline 16 & rs 12934235 & $5,637,396$ & 0.62 & 1.0 & 0.98 & 0.02 & 0.33 & 0.64 & 0.23 & $8.075 \times 10^{-4}$ & 0.11 \\
\hline 17 & rs 225218 & $27,923,447$ & 0.92 & 1.0 & 0.99 & 0.003 & 0.17 & 0.33 & 0.21 & $9.103 \times 10^{-6}$ & 0.42 \\
\hline 18 & rs906283 & $10,918,707$ & 0.15 & 1.0 & 0.99 & 0.008 & $9.993 \times 10^{-4}$ & 0.24 & 0.002 & $9.886 \times 10^{-5}$ & 0.36 \\
\hline 19 & rs 12151188 & $44,147,374$ & 0.40 & 1.0 & 0.96 & 0.75 & 0.01 & 0.78 & 0.03 & $7.579 \times 10^{-4}$ & 0.03 \\
\hline 20 & rs60303/5 & $35,003,238$ & 0.96 & 1.0 & 0.99 & 0.20 & 0.03 & 0.76 & 0.11 & $6.594 \times 10^{-5}$ & 0.15 \\
\hline 21 & rs991985 & $38,128,024$ & 0.66 & 1.0 & 0.99 & 0.002 & 0.10 & 0.33 & 0.05 & $1.996 \times 10^{-4}$ & 0.59 \\
\hline 22 & rs2880494 & $26,206,836$ & 0.92 & 1.0 & 0.99 & 0.605 & 0.11 & 0.58 & 0.28 & $2.832 \times 10^{-4}$ & 0.02 \\
\hline
\end{tabular}

${ }^{\mathrm{a}} \mathrm{Chr}$, chromosome; Unadj, Unadjusted p-values for main-effects association.

\section{Conclusion}

This case-control GWAA has yielded genomic regions exhibiting significantly different genotype frequencies between cases and controls that may contain genetic variants that predispose to RA and the regions identified may differ in the analyses with and without interactions. Our findings suggest that the association between SNPs and RA susceptibility varies significantly between men and women. In this GWAA of RA, characterization of how genes and the environment interact is important because the effects of covariates and genotype $x$ sex interactions on RA are significant. Similar tests for interaction with sex and other environmental variables should be included in future case-control design GWAA in RA. Our study also emphasizes the importance of accounting for population stratification in analyzing GWAS data. Simple IBS-based cluster analysis changed the outcome of the analysis substantially for some markers by accounting for the effects of stratification due to the presence of subpopulations.

\section{List of abbreviations used}

ADD: Additive; BH-FDR: Benjamini and Hochberg false discovery rate; BONF: Bonferroni correction; CDCV: Common-disease common-variant; DD: Dominant deviation; GAW: Genetic Analysis Workshop; GM: General; GWAA: Genome-wide association analysis; IBS: Identical-by-state; NARAC: North American Rheumatoid Arthritis Consortium; RA: Rheumatoid arthritis; SNP: Single-nucleotide polymorphism.

\section{Competing interests}

The authors declare that they have no competing interests.

\section{Authors' contributions}

RA conceived of the study, participated in its design, performed the statistical analyses including genome-wide association and interaction analysis and interpretation of results, and drafted the manuscript. EH participated in the statistical analysis. IDR participated in study design, 
funding, and editing manuscript. CPJ and RD helped in candidate gene identification and assisted in the data analysis. LA participated in the study design, helped in the genome-wide association analysis and interpretation of the results, and helped to draft the manuscript. AE participated in the design of the study, funding, assistance with data analysis, and editing manuscript. All authors read and approved the final manuscript.

\section{Acknowledgements}

The genetic analysis workshops are supported by NIH grants ROI GM03 1575, from the National Institute of General Medical Sciences. This study was also supported by R0I HD037 I5 I from the National Center for Medical Rehabilitation Research, and ROI HL085742 from the National Heart Lung and Blood Institute. We sincerely thank the GAWI6 organizers, data providers, and funding agencies.

This article has been published as part of BMC Proceedings Volume 3 Supplement 7, 2009: Genetic Analysis Workshop 16. The full contents of the supplement are available online at http://www.biomedcentral.com/ $|753-656| / 3$ ? issue $=S 7$.

\section{References}

I. Silman AJ and Hochberg MC: Epidemiology of the rheumatic diseases. New York, Oxford University Press; 1993.

2. Firestein GS: Evolving concepts of rheumatoid arthritis. Nature 2003, 423:356-36I.

3. Klareskog L, Stolt P, Lundberg K, Källberg H, Bengtsson C, Grunewald J, Rönnelid J, Harris HE, Ulfgren AK, RantapääDahlqvist S, Eklund $A$, Padyukov $L$ and Alfredsson $L$ : $\mathbf{A}$ new model for an etiology of rheumatoid arthritis: smoking may trigger HLA-DR (shared epitope)-restricted immune reactions to autoantigens modified by citrullination. Arthritis Rheum 2006, 54:38-46.

4. Bali D, Gourley S, Kostyu DD, Goel N, Bruce I, Bell A, Walker DJ, Tran K, Zhu DK, Costello T], Amos Cl and Seldin MF: Genetic analysis of multiplex rheumatoid arthritis families. Genes Immun 1999, 1:28-36.

5. MacGregor AJ, Snieder H, Rigby AS, Koskenvuo M, Kaprio J, Aho K and Silman Aj: Characterizing the quantitative genetic contribution to rheumatoid arthritis using data from twins. Arthritis Rheum 2000, 43:30-37.

6. Kurreeman FA, Padyukov L, Marques RB, Schrodi SJ, Seddighzadeh M, Stoeken-Rijsbergen G, Helm-van Mil van der AH, Allaart CF, Verduyn W, Houwing-Duistermaat J, Alfredsson L, Begovich AB, Klareskog L, Huizinga TW and Toes RE: A candidate gene approach identifies the TRAFI/C5 region as a risk factor for rheumatoid arthritis. PLoS Medicine 2007, 4:e278.

7. Gorman JD, Lum RF, Chen J], Suarez-Almazor ME, Thomson G and Criswell LA: Impact of shared epitope genotype and ethnicity on erosive disease: a meta-analysis of 3,240 rheumatoid arthritis patients. Arthritis Rheum 2004, 50:400-4I2.

8. Padyukov L, Silva C, Stolt P, Alfredsson L and Klareskog L: A geneenvironment interaction between smoking and shared epitope genes in HLA-DR provides a high risk of seropositive rheumatoid arthritis. Arthritis Rheum 2004, 50:3085-3092.

9. Purcell S, Neale B, Todd-Brown K, Thomas L, Ferreira MA, Bender D, Maller J, Sklar P, de Bakker PI, Daly MJ and Sham PC: PLINK: a tool set for whole-genome association and population-based linkage analyses. Am J Hum Genet 2007, 8 I:559-575.

10. Pritchard JK, Stephens M, Rosenberg NA and Donnelly P: Association mapping in structured populations. Am J Hum Genet 2000, 67:170-181.

I I. PLINK...Whole-genome Association Toolset. http://pngu.mgh. harvard.edu/purcell/plink/summary.shtml.

12. del Rincón I, Battafarano DF, Arroyo RA, Murphy FT and Escalante $A$ : Heterogeneity between men and women in the influence of the HLA-DRB I shared epitope on the clinical expression of rheumatoid arthritis. Arthritis Rheum 2002, 46: $|480-| 488$.

\section{Publish with Bio Med Central and every scientist can read your work free of charge}

"BioMed Central will be the most significant development for disseminating the results of biomedical research in our lifetime. "

Sir Paul Nurse, Cancer Research UK

Your research papers will be:

- available free of charge to the entire biomedical community

- peer reviewed and published immediately upon acceptance

- cited in PubMed and archived on PubMed Central

- yours - you keep the copyright
BioMedcentral 